\title{
A COMPARATIVE SURVEY STUDY ON ICT ACCESS AND USE OF INCOME-POOR AND NON-INCOME-POOR FLEMISH PEOPLE
}

\author{
Sarah Anrijs, Lieven De Marez and Koen Ponnet \\ Department of Communication Sciences, imec-mict-Ghent University \\ Miriam Makebaplein 1, 9000 Ghent, Belgium
}

\begin{abstract}
It remains unclear whether income-poor people have personal access to ICTs, whether they can use ICTs to fulfill basic needs, and which ICT problem solving strategies they can apply. Knowledge about the ICT resources of income-poor people is however crucial as governments, profit and non-profit organizations aim to digitize their services and administrations. Survey data were collected among 58 income-poor people $\left(58.6 \% \mathrm{men}, M_{\text {age }}=47.2, S D_{\text {age }}=11.5\right)$ and compared with a sample of 569 non-income-poor people $\left(48.7 \%\right.$ men, $\left.M_{\text {age }}=39.6, S D_{\text {age }}=13.2\right)$. Our results demonstrate that compared to non-income-poor people, significant more income-poor people do not have a computer, laptop or tablet and internet connection at home because they cannot afford it. Also, more income-poor people experience difficulties to look for a job online, to apply for financial benefits, or to search important information, while fewer income-poor people receive help or emotional support with ICT problems from others. Consequently, we recommend policy and organizations to invest in an internet and computer subsidy system and minimal non-digital services.
\end{abstract}

\section{KEYWORDS}

ICT, Digital Inequality, Digital Difficulties Scale, Poor People, Survey Study

\section{INTRODUCTION}

Because they are more hidden and harder to reach, people with an income below the poverty threshold (further called income-poor people), are often under or not represented, both in large-scale academic and non-academic survey studies about Information and Communication Technology (ICT) access and skills (e.g., Puspitasari and Ishii, 2016; Ragnedda et al., 2019; Van Deursen et al., 2019; Vandendriessche and De Marez, 2020). Consequently, it remains unclear whether income-poor people have personal access to ICTs, whether they can use ICTs to fulfill basic needs, and which ICT problem solving strategies they can apply. Knowledge about the ICT access and skills of income-poor people is however crucial as governments, profit and non-profit organizations increase the digitization of their services and administrations, - such as applying for a job, requesting information on insurances, or contacting the government or bank -, in order to improve efficiency or simplify processes.

Since the adoption of ICTs among the general population, concerns have risen that ICTs will lead to increasing inequalities (Hargittai, 2003). The unequal distribution and use of ICTs based on socio-demographic and socio-economic variables, such as income, gender, age, education, ethnicity, geography, and how this unequal distribution results in social (dis)advantages for individuals is the focus of digital inequality research (Helsper, 2012; Mossberger et al., 2003). While in the beginning of digital inequality research, the focus was on the unequal access of ICTs (Mossberger et al., 2003), throughout the years several authors have suggested that additional ICT resources are important to understand digital inequality. Indeed, it turned out that having access is a necessary but not sufficient condition to experience advantage from ICTs (Calderón Gómez, 2019; van Deursen and van Dijk, 2014), for example skills, use frequency, and use purposes were argued to be other ICT resources that may result into social advantage or disadvantage for individuals (Calderón Gómez, 2020; van Deursen and Helsper, 2015; van Deursen and van Dijk, 2014). Other studies also emphasized the importance of social support for ICT use in order to fully exploit advantages from it (Courtois and Verdegem, 2016; Helsper and van Deursen, 2017). 
Research within the domain of digital inequality has repeatedly demonstrated significant associations between ICT access, skills, use purposes, or support, on the one hand, and socio-economic and socio-demographic variables, such as income level, ethnicity, gender, age, education level or geography, on the other hand. Based on these studies, it has been concluded that lower levels or a lack of ICT access, skills or support are more prevalent among individuals with lower income, minorities, women, older people and lower educated people (Dodel and Mesch, 2018; Dolničar et al., 2018; Forenbacher et al., 2019; Puspitasari and Ishii, 2016; Ragnedda et al., 2019; Tsetsi and Rains, 2017). Although some studies have demonstrated that having a lower income, i.e., an income below average, is associated with lower levels of ICT access, attitudes and skills (e.g., Ragnedda et al., 2019; Tsetsi and Rains, 2017; Van Deursen et al., 2019), income-poor people are often not included in these survey studies.

The aim of the present study is to investigate the ICT resources of income-poor people. This study further adds to the literature in three ways. First, when measuring access, existing instruments ask people in a binary way whether or not they have a computer, internet or smartphone (e.g., Forenbacher et al., 2019; Puspitasari and Ishii, 2016; Ragnedda et al., 2019; Van Deursen et al., 2019), while some people might not have these by choice, and others might not have these by financial constraint. This distinction between lacking access by choice or by constraint is highly relevant, however until now, no studies have considered it. Second, different from previous research, but consistent with a study of Anrijs et al. (2020) this study will focus on ICT difficulties (i.e., having problems and questions in using ICTs for basic needs) instead of ICT skills and uses. Most instruments in the domain of digital inequality measure individuals' ICT competences or use purposes (e.g., Mingo and Bracciale, 2018; Ragnedda et al., 2019), for example existing scales measure if individuals know how to download a document, where to find information about child raising on the internet, or how to react on a news post, or they measure if individuals search for job vacancies on the internet, read information about elections, or buy products online (e.g., Kim and Glassman, 2013; Moret-Tatay et al., 2019; van Deursen et al., 2016; van Deursen and Helsper, 2015). Although the measurement of such skills and uses has proved to be valuable in order to understand digital inequality, it can be argued that it is unclear what the consequences are of not knowing how to download a document. Furthermore, some individuals may just not be interested in specific ICT uses such as reacting on blogs or buying products online. Therefore, the present study will investigate difficulties in using a smartphone or computer to fulfill basic needs, which allows us to determine who is at a disadvantage in a digitizing society (Anrijs et al., 2020). For example, if a health insurance organization decides that financial reimbursement of medical costs can solely be claimed online, having ICT difficulties may result into not receiving this benefit, which can be considered as a social disadvantage. Third, we argue that studies should also examine how individuals can solve their ICT problems or questions. As ICTs are constantly changing, it seems plausible that a significant amount of people experience ICT problems or questions on a regular basis, therefore ICT problem solving may be another important resource in a digitizing society.

\section{METHOD}

\subsection{Procedure}

This study is based on two cross-sectional surveys. Sample 1 consists of 58 income-poor people, and was completed in the period between February 2020 and mid-March 2020. Sample 2 consists a heterogeneous sample of 569 non-income-poor people, and was completed in October 2019. Inclusion criteria were that the respondents were between 18 and 64 years old and were non-students.

For the recruitment of respondents of sample 1, we worked together with twelve Flemish poverty organizations which organize social activities with poor people on regular times. After a short introduction of the organization's responsible person, all persons present at the activity were invited to participate in the paper-and-pencil survey. If desired, the survey questions and answer options were read out loud for the respondent by the researcher or an undergraduate student. In total, 114 persons completed the survey. However, 40 responses were ineligible as the respondents were older than 64 years. Further, only respondents with a monthly OECD equivalent income of 1250 euro or less were withhold. Considering the Flemish poverty threshold (www.statistiekvlaanderen.be) and the multiple definitions that exist for poverty (Bradshaw and Finch, 2003; Neckerman et al., 2016; Ponnet, 2014; Schenck-Fontaine and Panico, 2019), the present study 
considers individuals with a monthly OECD equivalent income of 1250 euro or less, income-poor people. An individual's monthly OECD equivalent income is the monthly total net income of the individual's household modified for the number of household members. The first adult receives a score 1, each additional adult or child of 14 years and older receives a score .5 , and each child under 14 years receives a score .3 . The total net household income is than divided by the sum of beforementioned scores (Ponnet and Van Crombrugge, 2015). The monthly OECD equivalent income allows us to compare respondents' income as if they were all single households. Eight respondents were not withhold as they did not answer the question "Which is the monthly total net income of your household?". Another eight respondents were not withhold as they had a monthly OECD equivalent income of more than 1250 euros. This resulted into a total number of 58 respondents for sample 1 .

For the recruitment of respondents of sample 2 we worked together with a professional research organization that has access to a panel of 300.000 Belgian individuals. In total, 8000 Flemish panel members received an email with a short study description, informed consent, and invitation to participate. We aimed to collect at a minimum 500 responses of non-income-poor individuals. In order to assure a heterogeneous sample, a stratified sampling procedure was applied. Based on the federal statistics of Belgium (www.statbel.fgov.be), we a priori stratified the data with regard to gender, age, and employment status, so that the proportion of the strata reflects the proportion of the Flemish population. This approach resulted into a total number of 569 respondents for sample 2 .

This study received ethical approval from the ethical board of the faculty of Social Sciences from [name of university blinded for purpose of review]. The demographics of both samples are included in Table 1 .

Table 1. Demographics of the samples of income-poor people and non-income-poor people

\begin{tabular}{|c|c|c|}
\hline \multirow{2}{*}{ Demographic variables } & $\begin{array}{l}\text { Income poor } \\
N=\mathbf{5 8}\end{array}$ & $\begin{array}{l}\text { Non-income-poor } \\
N=569\end{array}$ \\
\hline & \multicolumn{2}{|c|}{$n(\%)$} \\
\hline \multicolumn{3}{|l|}{ Gender } \\
\hline Man & $34(58.6 \%)$ & $277(48.7 \%)$ \\
\hline Woman & $24(41.4 \%)$ & $292(51.3 \%)$ \\
\hline Age in years (min-max / mean / standard deviation) & $18-64 / 47.2 / 11.5$ & $18-64$ / $39.6 / 13.2$ \\
\hline \multicolumn{3}{|l|}{ Employment status } \\
\hline I don't work & $47(81.0 \%)$ & $155(27.2 \%)$ \\
\hline I work part time & $7(12.1 \%)$ & $65(11.4 \%)$ \\
\hline I work full time & $4(6.9 \%)$ & $349(61.3 \%)$ \\
\hline \multicolumn{3}{|l|}{ Job seeker } \\
\hline Yes & $19(32.8 \%)$ & $76(13.4 \%)$ \\
\hline No & $39(67.2 \%)$ & $493(86.6 \%)$ \\
\hline \multicolumn{3}{|l|}{ Highest educational degree } \\
\hline Degree lower secondary education & $22(37.9 \%)$ & $86(15.1 \%)$ \\
\hline Degree secondary education & $22(37.9 \%)$ & $204(35.9 \%)$ \\
\hline Degree higher education & $14(24.1 \%)$ & $279(49.0 \%)$ \\
\hline
\end{tabular}

\subsection{Questionnaire}

We composed a simple, easy-to-administer questionnaire in plain language, both in paper-and-pencil and digital format.

ICT access - ownership and affordability. Respondents' personal access to ICT was measured for computer, internet at home, smartphone, and mobile internet, with four questions: "Do you have [a computer, laptop or tablet at home/an internet connection at home/a smartphone/mobile internet on your smartphone]?". Consistent with the material deprivation scale (Eurostat, 2020), answer options were $1=y e s, 2=$ no, because I don't want or need it, $3=$ no, because I cannot afford it. For the purpose of this study, answers were recoded in two dichotomous variables, (1) ICT ownership with $0=$ no, because I don't want or need it or I cannot afford it, and $1=y e s$, and (2) ICT affordability with $0=$ no, because I cannot afford it and $1=y e s$ or because I don't want or need it. 
Difficulties in using ICTs to reach basic needs. In order to measure which basic needs individuals have difficulties with to reach through using ICTs, we adopted the subscale Specific Digital Difficulties of the Digital Difficulties Scale (Anrijs et al., 2020). A sample item is: "If it would be necessary to do so, would you have difficulties to find job vacancies online, without help from others?". Respondents could select one of the following answers: 1 = no difficulties, 2 = rather no difficulties, $3=$ rather difficulties, $4=$ difficulties. Items were recoded as dichotomous variables with $0=$ no, (rather) not having difficulties and $1=$ yes, (rather) having difficulties.

ICT problem solving - perceived support and applied strategies. Perceived availability of support for solving ICT problems was questioned with two self-developed items. An example is "If it would be necessary or I would want it, I can go to others with questions or problems I have in using a smartphone, apps, websites or computer programs (e.g., family, friends or acquaintances)". Respondents scored these two items along a 5 -point scale ranging from $1=$ disagree to $5=$ agree. For the purpose of this study we recoded the answers in a dichotomous way, with $0=$ no, (rather) disagree or neither disagree/neither agree, and $1=$ yes, (rather) agree. In order to measure with strategies individuals apply to solve ICT problems or questions, we adopted three items from the Brief Cope Scale (Carver, 1997). An example is "What do you normally do when experiencing a problem or question in using ICTs? - I actively search for a solution and try things out". Answer options were $1=$ never, 2 = rarely, 3 =sometimes, $4=$ often, $5=$ always. We recoded the answers in a dichotomous way for the purpose of this study, with $0=n o$, never or rarely, $1=$ yes, sometimes, often or always.

\section{RESULTS}

Chi-square tests were used to assess differences in ICT resources between income-poor and non-income-poor people. In case that more than $20 \%$ of the expected counts were less than five, we employed Fisher's Exact Tests to analyze differences between groups. Statistical significance was set at $\mathrm{p}<.05$. One-tailed test statistics were used considering that previous studies have demonstrated positive associations between income levels on the one hand, and ICT access, attitudes, and skills on the other hand (Ragnedda et al., 2019; Tsetsi and Rains, 2017; Van Deursen et al., 2019). All statistical analyses were performed using IBM SPSS statistics (version 26).

With regard to ICT ownership (see Table 2), significant more income-poor people do not have a computer, laptop or tablet at home (46.4\%), an internet connection at home $(27.6 \%)$ or mobile internet on their smartphone $(37.9 \%$ ) than non-income-poor people (respectively, $2.3 \%, 0.2 \%$, and $15.3 \%$ ). No significant differences were found regarding smartphone ownership between income-poor people $(82.8 \%)$ and non-income-poor people $(88.9 \%)$. Also, significant more income-poor people reported not having a computer, laptop or tablet $(20.7 \%)$ or an internet connection $(15.5 \%)$ at home because they cannot afford it, than non-income-poor people (respectively, 2.1\% and 0.0\%). No significant differences were found regarding smartphone affordability and mobile internet connection affordability between income-poor people $3.4 \%$ cannot afford a smartphone, $10.3 \%$ cannot afford mobile internet) and non-income-poor people (3.9\% cannot afford a smartphone, $4.6 \%$ cannot afford mobile internet).

Furthermore, Table 2 demonstrates that difficulties in using ICTs to fulfill basic needs is more prevalent among income-poor people compared to non-income-poor people. More specifically, significant more income-poor people have difficulties to look for a job online (on average 39.1\%), to apply for financial benefits online (on average $42.3 \%$ ), or to find important information online (on average $30.4 \%$ ), than non-income-poor people (respectively, $10.2 \%, 19.5 \%$, and 10.2\%). With regard to ICT problem solving, no significant differences were found in perceived support, nor in the independent problem solving strategy, i.e., trying to find a solution oneself. Considering interdependent ICT problem solving or relying on others, significant more non-income-poor people ask others for help (79.4\%) or comfort and understanding (65.2\%) with ICT problems, than income-poor people (respectively $65.5 \%$ and $46.6 \%$ ). 
Table 2. Differences in ICT access, difficulties, and problem solving between income-poor people and non-income-poor people

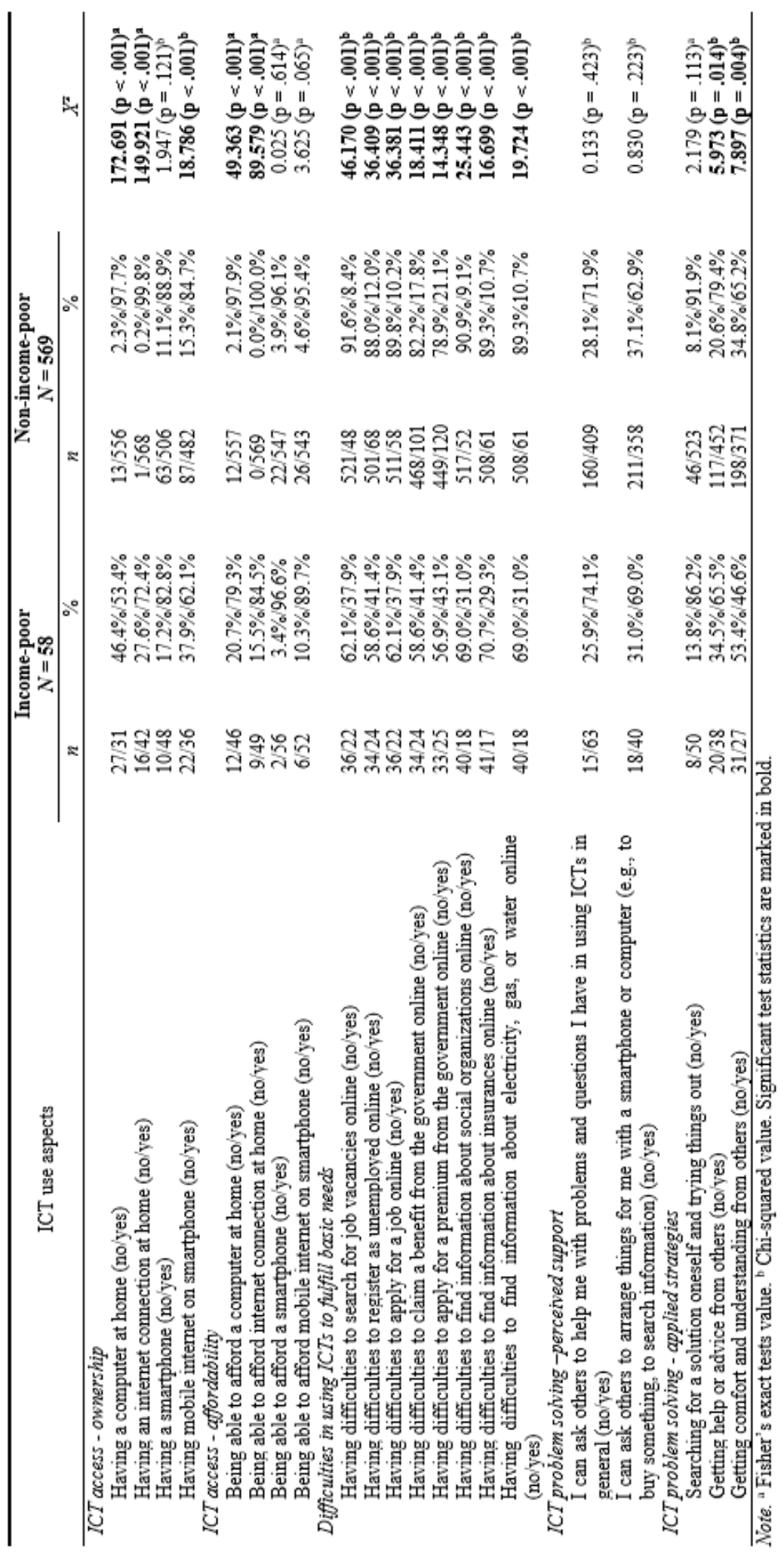




\section{CONCLUSION}

The aim of the present study was to investigate ICT access, difficulties and problem solving of income-poor people, compared with non-income-poor people. Investigating the ICT resources of income-poor people is important for future research and practice, as the former group is often underrepresented in survey studies, while they may benefit most from ICTs in order to improve their situation (e.g., finding a job, receiving financial benefits).

Building on previous research concerning ICT access, our study found that $46.4 \%$ of income-poor people do not have a computer, laptop or tablet at home, and $27.6 \%$ do not have an internet connection at home, these percentages are significant higher than those in our sample of non-income-poor people (respectively, $2.3 \%$ and $0.2 \%$ ). The findings are in line with previous studies which have found that individuals with a lower income are more likely not having a computer or laptop at home (Tsetsi and Rains, 2017) and that individuals with lower incomes have fewer ICT devices at home than individuals with higher incomes (Ragnedda et al., 2019). Further, our results demonstrated that smartphone ownership does not differ between income-poor $(82.8 \%)$ and income non-poor people $(88.9 \%)$, while having mobile internet for smartphone was significant less prevalent among income-poor $(62.1 \%)$ than non-income-poor people $(84.7 \%)$. The former finding is in line with a study by Forenbacher et al. (2019) who found that income was not associated with mobile phone ownership. With regard to affordability, our results demonstrated that significant more income-poor people reported not having a computer, laptop or tablet $(20.7 \%)$ or internet connection at home $(15.5 \%)$ because they cannot afford it, than non-income-poor people (respectively, $2.1 \%$ and $0.0 \%$ ), while no significant differences were found with regard to smartphone and mobile internet affordability. The present study is the first to make the distinction between not having ICTs by choice or by financial constraint, which is consistent with the material deprivation scale (Eurostat, 2020). We suggest future studies to also include this distinction, in order to better understand why people do not own ICTs and to allow comparisons between studies.

Extending previous studies that mainly focus on skills or use purposes (Dodel and Mesch, 2018; Moret-Tatay et al., 2019; Ragnedda et al., 2019; van Deursen and Helsper, 2015), the present study investigated difficulties in using a smartphone or computer to fulfill basic needs, because this may indicate who is at a social disadvantage in our society. Our results demonstrate that significant more income-poor people experience difficulties than non-income-poor people. More specifically, $39.1 \%$ of income-poor people have difficulties to look for a job online, $42.3 \%$ reports difficulties regarding applying for financial benefits online, and $30.4 \%$ have difficulties with finding important information online, within the sample of non-income-poor people these percentages are two to four times lower.

No significant differences were found between income-poor and non-income-poor people with regard to perceived support for ICT problem solving, which is in line with a study of Helsper and van Deursen (2017). Furthermore, no differences were found in independent ICT problem solving between income-poor and non-income-poor people, whereas significant differences were found in interdependent ICT problem solving, with more non-income-poor people asking for help or comfort and understanding than income-poor people do. Although our findings indicate that income-poor and non-income-poor have equal access to support, it is possibly that the quality of this support differs (Helsper and van Deursen, 2017), and therefore that they rely less frequently on their support sources. As only few studies have investigated ICT problem solving support (e.g., Dolničar et al., 2018; Helsper and van Deursen, 2017) and strategies (e.g., Courtois and Verdegem, 2016), and analysis are based on varying measures, cross-national studies with large representative samples and the same questions are necessary in order to allow comparisons and conclusions.

Although we believe this study has several strengths, some limitations should be kept in mind when interpreting the results of our study, such as the convenience sampling strategy, the presence of (student)-researchers during survey completion of income-poor people, and the reliance on self-report. These limitations might have resulted into participation bias, socially desirable answers, and overestimation or underestimation of difficulties. With regard to the latter, it has been demonstrated that higher-income groups showed smaller differences between their self-rated ICT skills and tested ICT skills, while lower-income groups showed larger differences (Bradlow et al., 2002). Future research could investigate such discrepancies between self-rated and effective difficulties of individuals based on, for example, observational studies. Additionally, in order to allow for better comparisons between populations and to advice policy decisions and interventions, researchers should aim for more uniform measurement and nationally representative samples of general populations and sub-populations such as older individuals, minorities, and disabled people. Preferable 
this is done based on both online and offline data collection, as properly mentioned by Hargittai (2010) and Litt (2013), merely online data collection may be problematic when studying digital inequality.

As our study demonstrated that income-poor people more often do not have a computer and internet connection at home, and that having difficulties using ICTs to fulfill basic needs is more prevalent among this group, we conclude that digitizing services and administrations, - such as applying for a job, requesting information on insurances, or contacting the government - may put income-poor people at an additionally social disadvantage compared to non-income-poor people. In order to mitigate this disadvantage, first, we suggest governments and policy makers to invest in a subsidy system which allows income-poor people or households to afford an internet connection at home. Second, telecom operators might borrow ICT devices at a social rate to income-poor households. Third, we recommend governments, non-profit and profit organizations to always provide a minimal non-digital service and administration in addition to their digital alternatives. This minimal non-digital services can be realized in several ways. For example, physical guidance to independent use of the digital service or administration can be provided for individuals who are uncapable to make use of the digital services. Another option might be a physical service whereby employees of the government or organization itself complete the digital service or administration instead of the individual who is uncapable.

\section{REFERENCES}

Anrijs, S. et al, 2020, "Development and psychometric properties of the Digital Difficulties Scale (DDS): An instrument to measure who is disadvantaged to fulfill basic needs by experiencing difficulties in using a smartphone or computer", edited by Chiesi, F.PLOS ONE, Vol. 15 No. 5, p. e0233891.

Bradlow, E.T. et al, 2002, "An assessment of basic computer proficiency among active internet users: Test construction, calibration, antecedents and consequences", Journal of Educational and Behavioral Statistics, Vol. 27 No. 3, pp. 237-253.

Bradshaw, J. and Finch, N., 2003, "Overlaps in dimensions of poverty”, Journal of Social Policy, pp. 513-525.

Calderón Gómez, D., 2019, "Technological capital and digital divide among young people: An intersectional approach", Journal of Youth Studies, Vol. 22 No. 7, pp. 941-958.

Calderón Gómez, D., 2020, "The third digital divide and Bourdieu: Bidirectional conversion of economic, cultural, and social capital to (and from) digital capital among young people in Madrid", New Media \& Society, p. 1461444820933252.

Carver, C.S., 1997, "You want to measure coping but your protocol'too long: Consider the brief cope", International Journal of Behavioral Medicine, Vol. 4 No. 1, p. 92.

Courtois, C. and Verdegem, P., 2016, "With a little help from my friends: An analysis of the role of social support in digital inequalities", New Media \& Society, Vol. 18 No. 8, pp. 1508-1527.

van Deursen, A. and van Dijk, J.A.G.M., 2014, "The digital divide shifts to differences in usage", New Media \& Society, Vol. 16 No. 3, pp. 507-526.

van Deursen, A. and Helsper, E.J., 2015, “The third-level digital divide: Who benefits most from being online?", in Robinson, L., Cotten, S.R., Schulz, J., Hale, T.M. and Williams, A. (Eds.), Studies in Media and Communications, Vol. 10, Emerald Group Publishing Limited, pp. 29-52.

van Deursen, A. et al, 2016, "Development and validation of the Internet Skills Scale (ISS)", Information, Communication \& Society, Vol. 19 No. 6, pp. 804-823.

Dodel, M. and Mesch, G., 2018, "Inequality in digital skills and the adoption of online safety behaviors", Information, Communication \& Society, Vol. 21 No. 5, pp. 712-728.

Dolničar, V. et al, 2018, "The role of social support networks in proxy Internet use from the intergenerational solidarity perspective", Telematics and Informatics, Vol. 35 No. 2, pp. 305-317.

Eurostat. 2020, "EU - Statistics on Income and Living Conditions microdata 2004-2018, release 2020, version 1", available at: https://doi.org/10.2907/EUSILC2004-2018V.1.

Forenbacher, I. et al, 2019, "Determinants of mobile phone ownership in Nigeria", Telecommunications Policy, Vol. 43 No. 7, p. 101812.

Hargittai, E., 2003, "The digital divide and what to do about is", New Economy Handbook, pp. 821-839.

Hargittai, E., 2010, "Digital Na(t)ives? Variation in Internet Skills and Uses among Members of the 'Net Generation"”, Sociological Inquiry, Vol. 80 No. 1, pp. 92-113. 
Helsper, E.J., 2012, “A corresponding fields model for the links between social and digital exclusion: A corresponding fields model for digital exclusion”, Communication Theory, Vol. 22 No. 4, pp. 403-426.

Helsper, E.J., and van Deursen, A. 2017, "Do the rich get digitally richer? Quantity and quality of support for digital engagement", Information, Communication \& Society, Vol. 20 No. 5, pp. 700-714.

Kim, Y. and Glassman, M., 2013, "Beyond search and communication: Development and validation of the Internet Self-efficacy Scale (ISS)", Computers in Human Behavior, Vol. 29 No. 4, pp. 1421-1429.

Litt, E., 2013, "Measuring users' internet skills: A review of past assessments and a look toward the future", New Media \& Society, Vol. 15 No. 4, pp. 612-630.

Mingo, I. and Bracciale, R., 2018, "The Matthew effect in the Italian digital context: The progressive marginalization of the 'poor"', Social Indicators Research, Vol. 135 No. 2, pp. 629-659.

Moret-Tatay, C. et al, 2019, "A Spanish adaptation of the computer and mobile device proficiency questionnaires (CPQ and MDPQ) for older adults", Frontiers in Psychology, Vol. 10, available at:https://doi.org/10.3389/fpsyg.2019.01165.

Mossberger, K. et al, 2003, Virtual Inequality: Beyond the Digital Divide, Georgetown University Press.

Neckerman, K.M. et al. 2016, "Beyond income poverty: measuring disadvantage in terms of material hardship and health", Academic Pediatrics, Vol. 16 No. 3, pp. S52-S59.

Ponnet, K., 2014, "Financial stress, parent functioning and adolescent problem behavior: An actor-partner interdependence approach to family stress processes in low-, middle-, and high-income families", Journal of Youth and Adolescence, Vol. 43 No. 10, pp. 1752-1769.

Ponnet, K. and Van Crombrugge, H., 2015, "Het is geen kwestie van slechte wil. Een vergelijking tussen laag- en midden- tot hooginkomensgezinnen inzake omgaan met financiële en relationele stress", Jaarboek Armoede En Sociale Uitsluiting, pp. 182-198.

Puspitasari, L. and Ishii, K., 2016, "Digital divides and mobile Internet in Indonesia: Impact of smartphones", Telematics and Informatics, Vol. 33 No. 2, pp. 472-483.

Ragnedda, M. et al, 2019, "Measuring Digital Capital: An empirical investigation", New Media \& Society, p. 146144481986960.

Schenck-Fontaine, A. and Panico, L., 2019, "Many kinds of poverty: Three dimensions of economic hardship, their combinations, and children's behavior problems", Demography, Vol. 56 No. 6, pp. 2279-2305.

Tsetsi, E. and Rains, S.A., 2017, "Smartphone Internet access and use: Extending the digital divide and usage gap", Mobile Media \& Communication, Vol. 5 No. 3, pp. 239-255.

Van Deursen, A. et al, 2019, "Digital inequalities in the Internet of Things: differences in attitudes, material access, skills, and usage", Information, Communication \& Society, Vol. 0 No. 0, pp. 1-19.

Vandendriessche, K. and De Marez, L., 2020, Imec.Digimeter 2019: Digitale Mediatrends in Vlaanderen, imec. 